\title{
A deterministic model for deteriorating items with displayed inventory level dependent demand rate incorporating marketing decisions with transportation cost
}

\author{
A. K. Bhunia ${ }^{\mathrm{a}^{*}}$ and Ali Akbar Shaikh ${ }^{\mathrm{b}}$
}

${ }^{a}$ Department of Mathematics, The University of Burdwan, Burdwan - 713104, West Bengal, India

${ }^{b}$ Department of Mathematics, Krishnagar Govt.College,Krishnagar,Nadia-741101, West Bengal, India

\begin{tabular}{|c|c|}
\hline A R T I C L E I N F O & A B S T R A T T \\
\hline $\begin{array}{l}\text { Article history: } \\
\text { Received 06 January } 2011 \\
\text { Accepted } 16 \text { March } 2011 \\
\text { Available online } \\
17 \text { March } 2011 \\
\text { Keywords: } \\
\text { Inventory } \\
\text { Deterioration } \\
\text { Marketing decision } \\
\text { Inventory level dependent demand } \\
\text { rate }\end{array}$ & $\begin{array}{l}\text { This paper deals with an inventory model, which considers the impact of marketing strategies } \\
\text { such as pricing and advertising as well as the displayed inventory level on the demand rate of } \\
\text { the system. In addition, the demand rate during the stock-out period differs from that during the } \\
\text { stock-in period by a function varied on the waiting time up to the beginning of the next cycle. } \\
\text { Shortage are allowed and partially backlogged. Here, the deterioration rate is assumed to follow } \\
\text { the Weibull distribution. Considering all these factors with others, different scenarios of the } \\
\text { system are investigated. To obtain the solutions of these cases and to illustrate the model, an } \\
\text { example is considered. Finally, to study the effects of changes of different parameters of the } \\
\text { system, sensitivity analyses have been carried out with respect to the different parameters of the } \\
\text { system. }\end{array}$ \\
\hline
\end{tabular}

Partially backlogged shortage

Non-linear programming

\section{Introduction}

Now-a-days, a product is promoted in the society through advertisement in the modern mass/electronic media and/or by the attractive display of units in the show-room at the market places. Glamorous display in large numbers with the help of modern light and electronic arrangements attracts the people and brings more customers for purchasing the items. Observing/investigating this effect, marketing researchers/practitioners have recognized the fact that, for certain items, displayed stock level has a positive impact on the consumption and the consumption rate goes down when the stock level is low. The study and analyses of inventory systems having stock-dependent consumption rate is one of the challenging and interesting problems for the market researchers. During the last few years, many researchers have carried out studies and analyses of this type of inventory system under various realistic situations. Baker and Urban (1988) first proposed this type of model. They reflected the idea that the demand rate would decline along with the stock-level throughout the cycle. In their model, power form of demand was considered for the on-hand inventory level dependent demand

* Corresponding author. Tel: +91-3213-254112

E-mail: bhuniaak@rediffmail.com (A. K. Bhunia) 
rate. Mondal and Phaujdar (1989a,b) developed independently this type of model considering the demand rate as a general function of the on-hand inventory level during stock-in and stock-out periods. Datta and Pal (1990) modified the concept of Baker and Urban (1988) by assuming that the demand rate of an item depends on the on-hand inventory level until a given level is achieved until the demand rate becomes constant. Since then, a lot of research works have been developed with extensions of this type of model considered by Urban (1992a,1995), Padmanabhan and Vrat (1995), Giri et al. (1996), Chang (2004), Pal et al.(2004,2006), Sana and Chaudhury (2004), Mondal et al.(2007), etc. Recently, Soni and Shah (2008) proposed an optimal ordering policy for retailer under progressive payment scheme for variable demand dependent on the inventory level. Goyal and Cheng (2009) formulated an ordering-transfer inventory model where demand rate depends on the displayed stock level.

In the present competitive market, the effect of marketing policies and conditions such as the price variations and the advertisement of an item change its demand pattern amongst the public. The propaganda and canvassing of an item by advertisement in the well-known media such as Newspaper, Magazine, Radio, T. V., Cinema through the sales representatives have a motivational effect on the people to buy more. In addition, the selling price of an item is one of the decisive factors in selecting an item for use. It is commonly seen that low selling price causes increase in demand whereas higher selling price has the reverse effect. Hence, it can be concluded that the demand of an item is a function of displayed inventory in a show-room, selling price of an item and the advertisement expenditures/frequency of advertisement. Kotler (1971) incorporated marketing policies into inventory decisions and discussed the relationship between economic ordering quantity and pricing decision. Ladany and Sternleib (1974) studied the effect of price variation on selling and consequently on economic order quantity (EOQ) but they did not consider the effect of advertisement. Subramanyam and Kumaraswamy (1981), Urban (1992b), Goyal and Gunasekaran (1995), Abad (1996) and Luo (1998) developed inventory models incorporating the effects of price variations and advertisement on demand rate of an item. In the recent years, very few researchers have considered this criterion in developing of their inventory models. In this connection, one may refer to the works of Mukhopadhyay et al. (2004), Pal et al. (2004, 2006), Pal et al. (2007), Mondal et al. (2007), Bhunia et al. (2011) with others.

When a purchasing manager places an order of items, it is important to realize that different types of costs including the transportation cost of the items should be taken into account. Therefore, the inventory and transportation costs depend on each other when the transportation cost is involved in inventory replenishment, It is well known that different transportation alternatives have different speed, reliability and cost characteristics. In most of the existing research, the transportation cost is not considered separately, it is included in the replenishment cost, which is independent of the order quantity. In realistic situation, the transportation cost is not independent of the ordered quantity. As a result, this cost cannot be ignored in the analysis of inventory system. Recently, very few researchers considered this cost into the analysis of lot-size determination. Baumol and Vinod (1970) first considered an inventory model of freight transport where by ordered quantity and transportation alternative can be jointly determined. Constable and Whybark (1978) assumed that the transportation cost per unit is independent of the order quantities. Buffa and Munn (1989) developed the model considering the transportation per unit to be a negative exponential function of the order quantity. Anily and Federgruin (1990) have considered the transportation cost in terms of truck loading cost. Krishnawamy et al. (1995) developed an EOQ model considering the transportation cost both for deterministic and stochastic demand cases. In these models, transportation cost per unit for the mode of transport (transport vehicle) is dependent on the quantity of the product. Recently, Pal et al. (2006), Mondal et al. (2007) and Bhunia et al. (2011) considered this cost under the assumption that the transportation cost is constant for transport vehicle ( of a given capacity) even if the quantity shipped is less than a transport vehicle load by some quantity. 
In this paper, an inventory model is developed for single deteriorating item by considering the marketing strategies such as pricing and advertising as well as glamorous display in the showroom. The deterioration rate follows the Weibull distribution and the demand rate of the system depends on the selling price, frequency of advertisement of item and the displayed inventory level in the showroom. Shortages are allowed and partially backlogged with a rate of demand on the waiting time of the beginning of the next cycle. The transportation cost is considered and it depends on the lot-size as well as the distance from the supplier's show-room. We discuss different scenarios of the system and an algorithm is proposed to find the solutions in these scenarios. The model is illustrated with a numerical example and to study the effects of changes of different parameters of the system, sensitivity analyses are carried out with respect to the different parameters of the system.

\section{Mathematical modeling and analysis}

\section{Assumptions and notations}

The following assumptions and notations are used to derive the mathematical model:

(i) Replenishments are instantaneous with a known, constant lead-time.

(ii) Shortages, if any, are allowed and partially backlogged with a rate dependent on the duration of waiting time to the beginning of the next cycle.

(iii) The entire lot is delivered in one batch.

(iv) The inventory planning horizon is infinite and the inventory system involves only one item and one stocking point.

(v) The deterioration occurs when the item is effectively stock-in and its rate follows the Weibull distribution.

(vi) The deteriorated units are not replaced.

(vii) The replenishment cost (ordering cost) is constant and does not include the transportation costs for replenishing the item.

(viii) The transportation cost is constant for a transport vehicle (of a given capacity) even if the quantity shipped is less than a transport vehicle load by some quantity.

(ix) Quantity discount is not allowed.

(x) The inventory carrying cost, $\mathrm{C}_{1}$ per unit per unit time, the shortage cost, $\mathrm{C}_{2}$ per unit per unit time, the purchase cost, $\mathrm{C}_{3}$ per unit, the ordering cost, $\mathrm{C}_{4}$ per order are known and constants.

(xi) $A$ represents the frequency of advertisement in the cycle length.

(xii) $\alpha, \beta$ are the parameters of the Weibull distribution with the probability density function of $f(t)=\alpha \beta t^{\beta-1} \exp \left(-\alpha t^{\beta}\right)$.

(xiii) The instantaneous rate of deterioration of the on-hand in any time is $\theta(t)$ with Weibull distribution. Therefore, $\theta(t)=\frac{f(t)}{1-F(t)}=\alpha \beta t^{\beta-1}$, where $0<\alpha<<1, \beta>0$ and $F(t)$ is the cumulative distribution function of Weibull distribution.

For $\beta=1, \theta(t)$ is constant,

$\beta>1, \theta(t)$ is increasing function in $t$,

$\beta<1, \theta(t)$ is decreasing function in $t$,

(xiv) $Q$ is the order quantity.

(xv) $\quad p$ is the selling price per unit of the item. $m$ be the mark-up rate of the selling price i.e., $p=m C_{3}$ ,$(m>1)$.

(xvi) $S$ is the highest stock level in the beginning of the cycle after fulfilling the backlogged quantity, if any and $R$ is the stock level of reorder point.

(xvii) The capacity of a transport vehicle is $k$ units. 
(xviii) $L$ is the distance between the show-room/shop and the source of the items/commodities from where items/commodities to be transported.

(xix) $C_{t}$ is the transportation cost for full load of the transport vehicle and $C_{t F}$ is the transportation cost per unit item.

(xx) $U$ is the upper break point. Some quantities less than $k$ but above $U$, the transportation cost for the whole quantities is $C_{t}$.

Hence $U=\left[C_{t} / C_{t F}\right](<k)$ where $\left[C_{t} / C_{t F}\right]$ represents the greatest integer value which is less than or equal to $C_{t} / C_{t F}$.

\section{The demand function}

In Baker and Urban (1988), it was reported that the demand rate is a function of the instantaneous stock level. In this situation, this rate is not constant. It changes with the change of stock level. Therefore, the demand rate will be greater during the beginning of an order cycle due to the higher stock-level and it decreases with the decrease of stock level. In this situation, it may be desirable to terminate the inventory cycle with some stock-in-hand in order to maintain higher demand rate. Again, the demand rate is not fully dependent on the stock level. It also depends on some marketing parameters (such as the selling price and the frequency of advertisement) which are discussed in the "Introduction" section.

The demand rate, $D(A, p, q)$ is deterministic and is a known function of marketing parameters which includes the selling price $(p)$ per unit and the number of times, the product/item to be advertised $(A)$. It also depends on the displayed inventory level in the show-room/shop within the inventory level $\mathrm{S}_{0}$ to $S_{1}$ and beyond this range; it becomes constant with respect to the displayed inventory level. In addition, the demand rate during the stock-out period is different from the same during the stock-in period and the rate depends on the length of the waiting time to the beginning of the next cycle. It takes the following form:

$$
D(A, p, q)=\left\{\begin{array}{llc}
f\left(A, p, S_{1}\right) & \text { for } & q>S_{1} \\
f(A, p, q) & \text { for } & \mathrm{S}_{0}<q<S_{1} \\
f\left(A, p, S_{0}\right) & \text { for } & 0 \leq q \leq S_{0} \\
\frac{f\left(A, p, S_{0}\right)}{1+\delta(T-t)} & \text { for } & \mathrm{q}<0
\end{array}\right.
$$

where $0<\delta \leq 1$ and $f(A, p, q)$ is a function of $A, p$ and $q$ and can be represented in different forms. It may be of the power form $\left(\alpha q^{\beta}\right)$, exponential form $(\alpha \exp (\beta q))$, linear form $(\alpha+\beta q)$ with respect to the instantaneous inventory level. The power form results zero demand rate when the inventory level reaches to zero. Note that the demand rate cannot be zero. Therefore, the demand rate cannot fully depend on the instantaneous inventory level. Due to some realistic factors, such as goodwill, good quality, genuine price-level of the goods, locality of the shop, etc, a limited number (may be considered as constant) of customers arrive to purchase the goods. Hence, the demand rate of an item of a particular shop will be more appropriate if the linear form of the demand rate with respect to the stock level. In this situation, we consider the linear form of the displayed inventory, the selling price of an item and power form of the frequency of the advertisement for $f(A, p, q)$ with the form of $f(A, p, q)=A^{\gamma}(a-b p+c q)$ where $a, b, c, \gamma \geq 0$.

\section{Transportation Cost}

When the ordered quantity is greater than one integral transport vehicle load, the ordered quantity $Q$ can be expressed as $Q=n k+k_{1} q$ where $n=0$ or any positive integer; $k_{1}=0$ or 1 and $q<k$. 
In that case, two situations may arise:

(i) $n k<Q \leq n k+U \quad$ (ii) $n k+U<Q \leq(n+1) k$.

Hence, the total transportation cost is given by

$$
C_{\text {tran }}=\left\{\begin{array}{cc}
n C_{t}+(q-n k) C_{t F}, & n k<Q \leq n k+U \\
(n+1) C_{t} . & n k+U<Q<(n+1) k
\end{array}\right.
$$

\section{The mathematical model}

To analyze this model, nine different scenarios may arise according to the relative size of $S_{0}, S_{1}$, the highest inventory level $S$ in the beginning of the cycle after fulfilling the backlogged quantity and the inventory level $R$ of reorder point.

\begin{tabular}{|c|c|c|c|c|}
\hline Scenario 1 & $S \leq S_{0}$ and $R \geq 0$ & $0 \leq R \leq S_{0}<S<S_{1}$ & Scenario 7 & $S>S_{1}$ and $0 \leq R<S_{0}$ \\
\hline Scenario 2 & $S \leq S_{0}$ and $R<0$ & Scenario $5 S_{0} \leq S<S_{1}$ and $R<0$ & Scenario 8 & $S_{1}<R<S$ \\
\hline Scenario 3 & $S_{0}<R<S<S_{1}$ & $S>S_{1}$ and $R>S_{0}$ & Scenario 9 & $S>S_{1}$ and $R<0$ \\
\hline
\end{tabular}

In Scenario $1 \& 2$, the demand rate is always constant, the inventory level is never large enough to realize the inventory level dependent demand rate (see Fig. 1 \& 2). In Scenario 3, the demand rate never becomes constant; the inventory is replenished before reaching the inventory level $S_{0}$ (see Fig.

3). In Scenario 4, the stock-out position never occurs since the reorder point is non-negative (see Fig. 4). In the situation of Scenario 5, the inventory level-dependent demand rate is observed where the inventory level drops from $S_{1}$ to $S_{0}$. For the decreasing inventory level from $S_{0}$ to 0 , there is a constant demand rate and during the stock-out situation, the decreased demand rate is realized (see Fig. 5). In Scenario 6, the reordered point is non-negative and the demand rate is constant when the inventory level drops from $S_{1}$ to $S$. Then it becomes inventory-level dependent up to the reorder point (see Fig. 6). In Scenario 7, initially the demand rate is constant, then it becomes inventory-level dependent and next it is constant (see Fig. 7). In Scenario 8, the demand rate is constant. In this case, the initial inventory level is greater than $S_{1}$. In Scenario 9, all possible forms of demand rate are considered and the stock-out condition is reported (see Fig. 9).

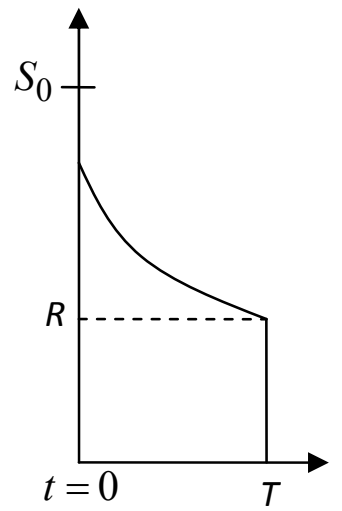

Fig. 1. The inventory in Scenario 1

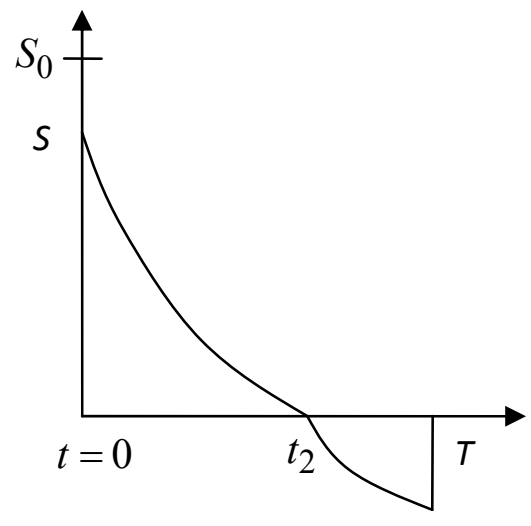

Fig. 2. The inventory in Scenario 2

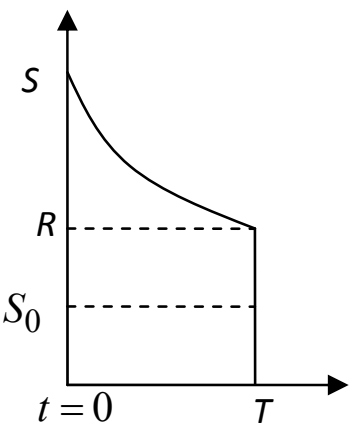

Fig. 3. The inventory in Scenario 3 


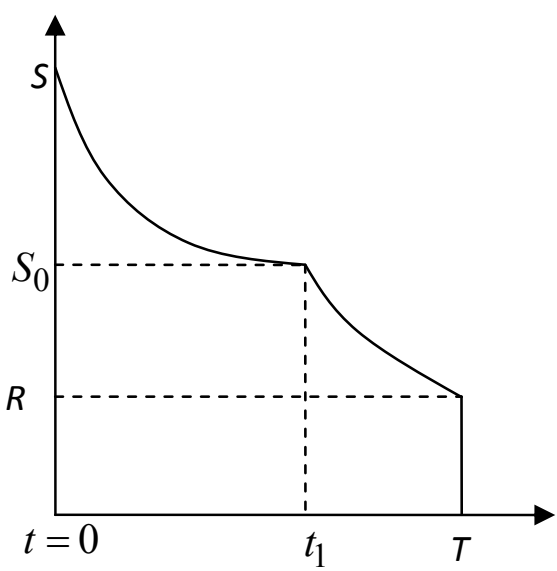

Fig. 4. Inventory situation of Scenario 4

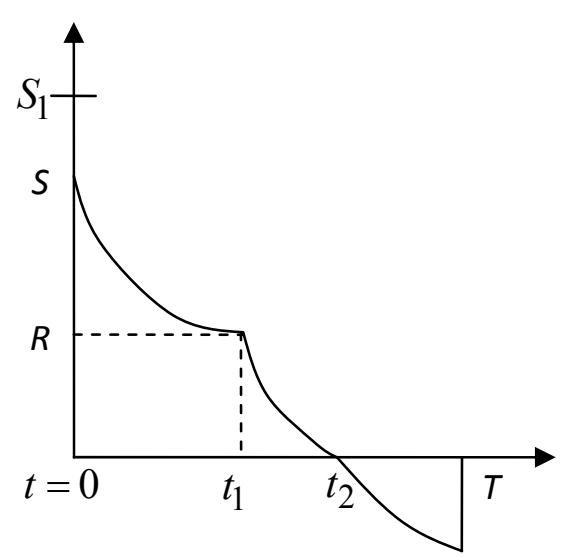

Fig. 5. Inventory situation of Scenario 5

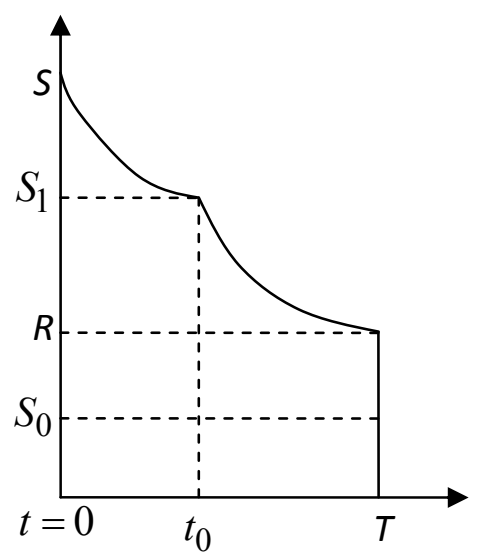

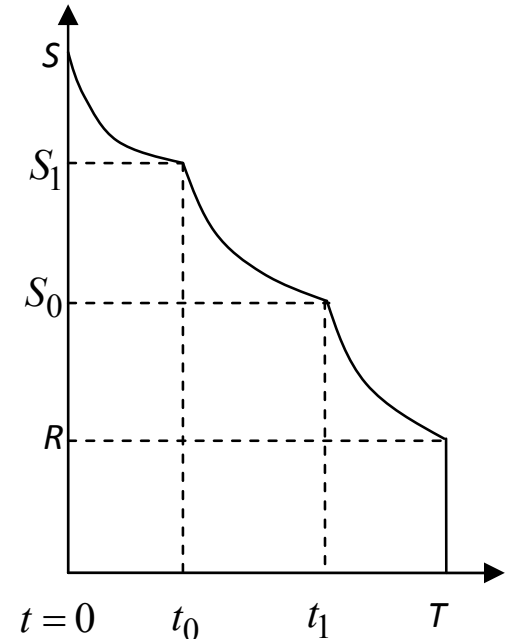

Fig. 7. Inventory situation of Scenario7

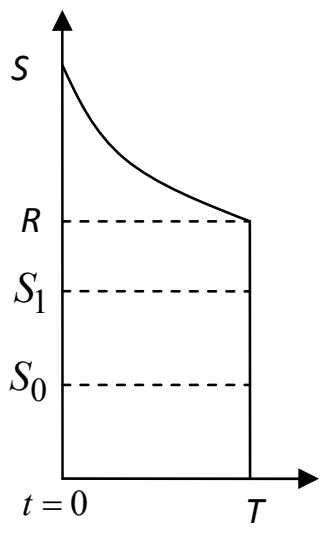

Fig. 8. Inventory situation of Scenario 8

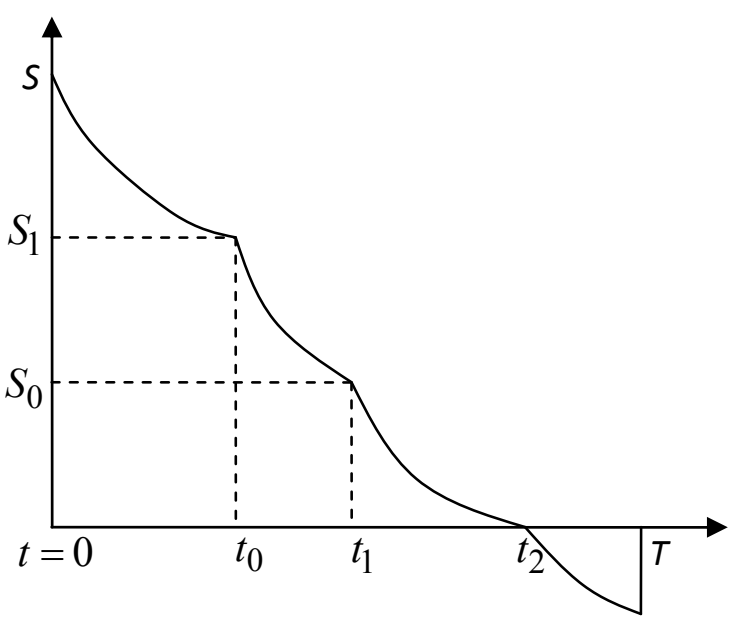

Fig. 9. Inventory situation of Scenario 9

Now we shall study the Scenario 9 in detail.

Scenario 9: $S>S_{1}$ and $R<0$

In this scenario, the order quantity is $Q=S+|R|$. The inventory level depletes with the time due to fluctuating the demand of the customer and the deterioration effect of the item. The differential equations representing the instantaneous inventory level $q(t)$ of the system are given by

$$
\begin{aligned}
& q^{\prime}(t)+\theta(t) q(t)=-A^{\gamma}\left(a-b p+c S_{1}\right), \quad 0 \leq t \leq t_{0} \\
& q^{\prime}(t)+\theta(t) q(t)=-A^{\gamma}(a-b p+c q), \quad t_{0}<t \leq t_{1} \\
& q^{\prime}(t)+\theta(t) q(t)=-A^{\gamma}\left(a-b p+c S_{0}\right), \quad t_{1}<t \leq t_{2} \\
& q^{\prime}(t)=-\frac{A^{\gamma}\left(a-b p+c S_{0}\right)}{1+\delta(T-t)}, \quad t_{2}<t \leq T
\end{aligned}
$$

where 


$$
q(t)=S \text { at } t=0, q(t)=S_{1} \text { at } t=t_{0}, q(t)=S_{0} \text { at } t=t_{1} .
$$

Again,

$q(t)=0$ at $t=t_{2}$ and $q(t)=R$ at $t=T$.

Also, $q(t)$ is continuous at $t=t_{0}, t_{1}$ and $t_{2}$. Using the boundary conditions (5) and (6), the solutions of the differential Eq. (1)-(4) are given by

$$
\begin{aligned}
q(t) & =\exp \left(-\alpha t^{\beta}\right)\left[S-A^{\gamma}\left(a-b p+c S_{1}\right) \int_{0}^{t} \exp \left(\alpha u^{\beta}\right) d u\right], \quad 0 \leq t \leq t_{0} \\
= & \exp \left(-\alpha t^{\beta}-A^{\gamma} c t\right)\left[S_{0} \exp \left(\alpha t_{1}^{\beta}+A^{\gamma} c t_{1}\right)+A^{\gamma}(a-b p) \int_{t}^{t_{1}} \exp \left(\alpha u^{\beta}+A^{\gamma} c u\right) d u\right], t_{0}<t \leq t_{1} \\
= & A^{\gamma}\left(a-b p+c S_{0}\right) \exp \left(-\alpha t^{\beta}\right)^{t_{2}} \exp \left(\alpha u^{\beta}\right) d u, \quad t_{1}<t \leq t_{2} \\
= & R+\frac{1}{\delta} A^{\gamma}\left(a-b p+c S_{0}\right) \log |1+\delta(T-t)|, \quad t_{2}<t \leq T
\end{aligned}
$$

Using the condition $q(t)=S_{1}$ at $t=t_{0}$ in Eq. (7), we have

$$
S_{1}=\exp \left(-\alpha t_{0}^{\beta}\right)\left[S-A^{\gamma}\left(a-b p+c S_{1}\right) \int_{0}^{t_{0}} \exp \left(\alpha u^{\beta}\right) d u\right]
$$

which implies

$$
S=S_{1} \exp \left(-\alpha t_{0}^{\beta}\right)+A^{\gamma}\left(a-b p+c S_{1}\right) \int_{0}^{t_{0}} \exp \left(\alpha u^{\beta}\right) d u
$$

From the continuity conditions of $q(t)$ at $t=t_{0}, t_{1}$ and $t_{2}$, we get the following three relations from Eq. (8), Eq. (9) and Eq. (10).

$$
\begin{aligned}
& S_{1}=\exp \left(-\alpha t_{0}^{\beta}-A^{\gamma} c t_{0}\right)\left[S_{0} \exp \left(\alpha t_{1}^{\beta}+A^{\gamma} c t_{1}\right)+A^{\gamma}(a-b p) \int_{t_{0}}^{t_{1}} \exp \left(\alpha u^{\beta}+A^{\gamma} c u\right) d u\right] . \\
& S_{0}=A^{\gamma}\left(a-b p+c S_{0}\right) \exp \left(-\alpha t_{0}^{\beta}\right) \int_{t_{1}}^{t_{2}} \exp \left(\alpha u^{\beta}\right) d u \\
& R=\frac{1}{\delta} A^{\gamma}\left(a-b p+c S_{0}\right) \log \left|1+\delta\left(T-t_{2}\right)\right|
\end{aligned}
$$

During the inventory cycle, deteriorated units have to be separated. The amount of inventory deteriorated during the cycle can be derived by integrating the product of the deterioration rate and the inventory level over the entire cycle. It is the difference between the initial on-hand inventory and 
the total selling units during the stock-in period of the entire cycle. Hence, the total number of deteriorated units over the cycle is given by

$$
D^{\prime}=\int_{0}^{t_{2}} \theta(t) q(t) d t=S-\int_{0}^{t_{2}} D(A, p, q) d t=S-A^{\gamma}(a-b p) t_{2}-A^{\gamma} c\left\{t_{0} S_{1}+S_{0}\left(t_{2}-t_{1}\right)\right\}-A^{\gamma} c \int_{0}^{t_{1}} q(t) d t
$$

The cost function

The total cost in a cycle consists of the following components:

(i) Ordering cost; (ii) inventory holding cost; (iii) inventory shortage cost; (iv) transportation cost;

(v) purchase cost; (vi) advertisement cost

Now the total inventory holding cost $C_{\text {hol }}$ over the entire cycle is given by

$C_{h o l}=C_{1}\left[\int_{0}^{t_{0}} q(t) d t+\int_{t_{0}}^{t_{1}} q(t) d t+\int_{t_{1}}^{t_{2}} q(t) d t\right]$. Again, the total shortage cost $C_{\text {sho }}$ over the entire cycle is given by

$$
C_{\text {sho }}=C_{2}\left[R\left(t_{2}-T\right)+\left\{\left(T-t_{2}\right)-\frac{1+\delta\left(T-t_{2}\right)}{\delta} \log \left|1+\delta\left(T-t_{2}\right)\right|\right\} \cdot \frac{1}{\delta} A^{\gamma}\left(a-b p+c S_{0}\right)\right]
$$

The total cost (TC) of this scenario is consists of ordering, purchasing, holding, shortage, advertisement and transportation items as follows,

$$
T C=C_{4}+C_{3}(S+|R|)+C_{h o l}+C_{s h o}+C_{t r a n}+C_{a d v}
$$

where

$$
C_{\text {tran }}=\left\{\begin{array}{cc}
n C_{t}+(S+|R|-n k) C_{t F}, & n k<S+|R| \leq n k+U \\
(n+1) C_{t} & n k+U<S+|R| \leq(n+1) k
\end{array}\right.
$$

The net profit for the entire system is given by

$$
X=p\left\{(S+|R|)-D^{\prime}\right\}-C_{3}(S+|R|)-C_{\text {hol }}-C_{\text {sho }}-C_{\text {tran }}-C_{a d v}-C_{4}
$$

Therefore, the profit function $Z_{9}\left(m, n, A, t_{0}, t_{1}, t_{2}, T\right)$ (average profit per unit time for the entire cycle) of the Scenario-9 is given by

$Z_{9}\left(m, n, A, t_{0}, t_{1}, t_{2}, T\right)=X / T$

Here, the profit function is a function of five continuous variables $m, t_{0}, t_{1}, t_{2}, T$ and two integer variables $n, A$.

Proposition: The profit function $Z_{9}\left(m, n, A, t_{0}, t_{1}, t_{2}, T\right)$ in Eq. (20) is a non-decreasing function with respect to $m$.

The proof of the proposition can be done once we show $\frac{\partial Z_{9}}{\partial m}>0$. 
Our aim is to find the optimal values of $S, R$ and $T$ by maximizing the profit function $Z_{9}$ for the fixed value of mark-up rate $m$. Therefore, we have to maximize $Z_{9}$ with respect to $n, A, t_{0}, t_{1}, t_{2}$ and $T$ for fixed mark-up rate $m$. Therefore our problem is

Maximize $Z_{9}\left(n, A, t_{0}, t_{1}, t_{2}, T\right)=\left[p\left(Q-D^{\prime}\right)-C_{3} Q-C_{h o l}-C_{s h o}-C_{t r a n}-C_{a d v}-C_{4}\right] / T$

subject to

$S_{1}-\exp \left(-\alpha t_{0}^{\beta}-A^{\gamma} c t_{0}\right)\left[S_{0} \exp \left(\alpha t_{1}^{\beta}+A^{\gamma} c t_{1}\right)+A^{\gamma}(a-b p) \int_{t_{0}}^{t_{1}} \exp \left(\alpha u^{\beta}+A^{\gamma} c u\right) d u\right]=0$

$S_{0}-A^{\gamma}\left(a-b p+c S_{0}\right) \exp \left(-\alpha t_{0}^{\beta}\right) \int_{t_{1}}^{t_{2}} \exp \left(\alpha u^{\beta}\right) d u=0$

$S>S_{1}, R<0, T>t_{2}>t_{1}>t_{0}>0$ and $n, A>0$ and $n, A$ are integers.

where

$$
C_{\text {tran }}=\left\{\begin{array}{cc}
n C_{t}+(S+|R|-n k) C_{t F}, & n k<S+|R| \leq n k+U \\
(n+1) C_{t} & n k+U<S+|R| \leq(n+1) k
\end{array}\right.
$$

The above problem can be solved by using the well known generalized reduced gradient (GRG) method and the following algorithm.

\section{Algorithm}

Step-1: Input all the parameters,

Step-2: Calculate the value of $U$,

Step-3: Using GRG method, solve the above problem by taking the transportation cost for first situation $(n k<S+|R| \leq n k+U)$.

Step-4: If $S+|R|$ lies in the interval $(n k<S+|R| \leq n k+U)$, then this is the optimal policy of Scenario-9 and go to Step-7. Otherwise, go to Step-5,

Step-5: Using GRG method, solve the above problem by taking the transportation cost for second situation $(n k+U<S+|R| \leq(n+1) k)$,

Step-6: If $S+|R|$ lies in the interval $(n k+U<S+|R| \leq(n+1) k)$, then this is the optimal policy of Scenario-9,

Step-7: Stop.

For a particular value of $m$, the maximum value of $Z_{9}$ is not the optimal value in the system. For other scenarios, the objective function are as follows (the formulation of profit functions $Z_{j}, j$ represents the number of scenario, are given in Appendix):

$$
Z_{1}=\left[p\left(Q-D^{\prime}\right)-C_{3} Q-C_{\text {hol }}-C_{\text {tran }}-C_{a d v}-C_{4}\right] / T
$$




$$
\begin{aligned}
& Z_{2}=\left[p\left(Q-D^{\prime}\right)-C_{3} Q-C_{h o l}-C_{\text {sho }}-C_{\text {tran }}-C_{a d v}-C_{4}\right] / T \\
& Z_{3}=\left[p\left(Q-D^{\prime}\right)-C_{3} Q-C_{h o l}-C_{t r a n}-C_{a d v}-C_{4}\right] / T \\
& Z_{4}=\left[p\left(Q-D^{\prime}\right)-C_{3} Q-C_{h o l}-C_{t r a n}-C_{a d v}-C_{4}\right] / T \\
& Z_{5}=\left[p\left(Q-D^{\prime}\right)-C_{3} Q-C_{h o l}-C_{\text {sho }}-C_{t r a n}-C_{a d v}-C_{4}\right] / T \\
& Z_{6}=\left[p\left(Q-D^{\prime}\right)-C_{3} Q-C_{h o l}-C_{t r a n}-C_{a d v}-C_{4}\right] / T \\
& Z_{7}=\left[p\left(Q-D^{\prime}\right)-C_{3} Q-C_{h o l}-C_{t r a n}-C_{a d v}-C_{4}\right] / T \\
& Z_{8}=\left[p\left(Q-D^{\prime}\right)-C_{3} Q-C_{h o l}-C_{t r a n}-C_{a d v}-C_{4}\right] / T
\end{aligned}
$$

Optimal solution of the system

The optimal solution of the inventory system can be determined from the solution of each case:

$$
Z^{*}=\max Z_{j}(\forall j=1,2, \cdots, 9)
$$

\section{Numerical Illustrations}

To illustrate the developed model, a numerical example with the following values of different parameters has been considered. Let $C_{1}=\$ 1.00$ per unit per unit time, $C_{2}=\$ 20.00$ per unit per unit time, $C_{3}=\$ 25.00$ per unit, $C_{4}=\$ 100.00$ per order, $C_{t}=\$ 100.00$ per load, $C_{t F}=\$ 1.25$ per unit, $\mathrm{C}_{5}=\$ 100.00$ per advertisement, $S_{0}=50.00, S_{1}=250.00, a=250.00, b=0.30, c=0.30, \alpha=0.10, \gamma=0.30, \delta$ $=1.50, \beta=1.00, k=100.00$ unit, $L=50.00 \mathrm{~km}$.

The parameter values consider here are realistic, the parameter values considered here are not taken from any case study of an existing inventory system, but these are realistic. According to the proposed algorithm, the optimal solution has been obtained with the help of GRG method for different values of $m$. The optimum values of $n, A, t_{0}, t_{1}, t_{2}, T, S$ and $R$ along with maximum average profit are displayed in Table 1.

\section{Table 1}

Optimal solution for different values of mark-up rate $m$

\begin{tabular}{lllllllll}
\hline$m$ & $A$ & $S$ & $R$ & $t_{0}$ & $t_{1}$ & $t_{2}$ & $T$ & $Z$ \\
\hline 1.25 & 6 & 456.4945 & 43.50552 & 0.35878 & 0.7576 & 0.87126 & 0.97848 & 1130.15 \\
1.27 & 7 & 549.9608 & 50.03919 & 0.49543 & 0.8770 & 0.9855 & 1.1042 & 1379.82 \\
1.30 & 10 & 644.1450 & 55.85497 & 0.5852 & 0.9292 & 1.0269 & 1.1461 & 1792.35 \\
1.32 & 12 & 738.0510 & 61.94902 & 0.6843 & 1.0106 & 1.1032 & 1.2290 & 2086.19 \\
1.35 & 15 & 833.6037 & 66.39628 & 0.76455 & 1.0704 & 1.1571 & 1.2833 & 2562.71 \\
\hline
\end{tabular}

\section{Sensitivity analysis}

For the numerical example mentioned earlier, sensitivity analyses have been done numerically to study the effect of under or over estimation of different parameters like backlogging parameter $(\delta)$, the demand rate parameters $(a, b, c)$, inventory carrying cost $\left(C_{1}\right)$, shortage cost $\left(C_{2}\right)$, purchase cost $\left(C_{3}\right)$ and ordering cost $\left(C_{4}\right)$ on the optimal values of frequency of advertisement $(A)$, reorder level $(R)$, initial stock-level $(S)$, different time points and the average profit function $Z$. These analyses have 
been carried out by changing (increasing and decreasing) the parameters from $-20 \%$ to $+20 \%$ taken one parameter at a time and making the other parameters at their original values. The results of these analyses are given in Table 2.

Table 2

Sensitivity analysis with respect to different parameters

\begin{tabular}{|c|c|c|c|c|c|c|c|c|c|}
\hline \multirow[b]{2}{*}{ Parameter } & \multirow{2}{*}{$\begin{array}{l}\% \text { changes of } \\
\text { parameters }\end{array}$} & \multirow{2}{*}{$\begin{array}{l}\% \text { changes } \\
\text { in } Z^{*}\end{array}$} & \multirow{2}{*}{$A^{*}$} & \multicolumn{6}{|c|}{$\%$ changes in } \\
\hline & & & & $S^{*}$ & $R^{*}$ & $t_{0}^{*}$ & $t_{1}^{*}$ & $t_{2}{ }^{*}$ & $T^{*}$ \\
\hline \multirow{4}{*}{$C_{1}$} & -20 & 3.07 & 10 & 0.57 & -6.59 & 0.91 & 0.57 & 0.52 & -0.27 \\
\hline & -10 & 1.53 & 10 & 0.29 & -3.29 & 0.44 & 0.28 & 0.25 & -0.14 \\
\hline & 10 & -1.74 & 9 & -14.4 & -13.01 & -20.69 & -11.87 & -10.44 & -10.49 \\
\hline & 20 & -3.04 & 9 & -14.64 & -10.2 & -21.1 & -12.12 & -10.66 & -10.37 \\
\hline \multirow{4}{*}{$C_{2}$} & -20 & 0.73 & 10 & -1.31 & 15.11 & -2.08 & -1.31 & -1.19 & 0.66 \\
\hline & -10 & 0.34 & 10 & -0.61 & 7.02 & -0.97 & -0.61 & -0.56 & 0.31 \\
\hline & 10 & -0.3 & 10 & 0.53 & -6.16 & 0.84 & 0.54 & 0.48 & -0.25 \\
\hline & 20 & -0.56 & 10 & 1.01 & -11.6 & 1.59 & 1 & 0.91 & -0.48 \\
\hline \multirow{4}{*}{$C_{4}$} & -20 & 0.97 & 10 & 0.04 & -0.43 & 0.05 & 0.03 & 0.04 & -0.02 \\
\hline & -10 & 0.49 & 10 & 0.02 & -0.21 & 0.02 & 0.01 & 0.02 & -0.01 \\
\hline & 10 & -0.49 & 10 & -0.02 & 0.21 & -0.03 & -0.01 & -0.02 & 0.01 \\
\hline & 20 & -0.97 & 10 & -0.04 & 0.43 & -0.07 & -0.04 & -0.03 & 0.02 \\
\hline \multirow{4}{*}{$C_{5}$} & -20 & 11.08 & 13 & 0.13 & -1.49 & -6.92 & $\begin{array}{l}-7.09 \\
\end{array}$ & -7.14 & $\begin{array}{l}-7.39 \\
\end{array}$ \\
\hline & -10 & 5.17 & 11 & 0.09 & -1.05 & -2.51 & -2.59 & -2.61 & -2.77 \\
\hline & 10 & -4.53 & 9 & -0.06 & 0.68 & 2.90 & 2.98 & 3.00 & 3.14 \\
\hline & 20 & -8.42 & 7 & -14.21 & -15.14 & -14.56 & -5.1 & -3.54 & -3.80 \\
\hline \multirow{4}{*}{$a$} & -20 & -55.62 & 30 & 69.01 & 99.38 & 78.67 & 44.97 & 39.69 & 45 \\
\hline & -10 & -13.28 & 8 & -13.95 & -18.2 & -10.61 & -0.46 & 1.33 & 0.86 \\
\hline & 10 & 13.54 & 10 & -0.1 & 1.18 & -7.06 & -7.38 & -7.52 & -7.62 \\
\hline & 20 & 27.55 & 11 & 13.91 & 18.58 & 3.47 & -4.12 & -5.5 & -5.34 \\
\hline \multirow{4}{*}{$b$} & -20 & 1.06 & 10 & -0.01 & 0.1 & -0.6 & -0.62 & -0.63 & -0.64 \\
\hline & -10 & 0.53 & 10 & 0 & 0.05 & -0.29 & -0.31 & -0.32 & -0.31 \\
\hline & 10 & -0.53 & 10 & 0 & -0.05 & 0.29 & 0.31 & 0.32 & 0.32 \\
\hline & 20 & -1.06 & 10 & 0.01 & -0.1 & 0.58 & 0.62 & 0.63 & 0.65 \\
\hline \multirow{4}{*}{$c$} & -20 & -6.08 & 9 & -14.82 & -8.18 & -17.7 & -8.82 & -7.57 & -7.24 \\
\hline & -10 & -3.25 & 9 & -14.48 & -12.04 & -19.02 & -10.25 & -8.91 & -8.95 \\
\hline & 10 & 3.08 & 10 & 0.35 & -4.06 & -1.64 & -1.56 & -1.47 & -1.83 \\
\hline & 20 & 6.15 & 10 & 0.7 & -8.07 & -3.2 & -3.06 & -2.88 & -3.6 \\
\hline \multirow{4}{*}{$\alpha$} & -20 & 8.86 & 11 & 15.85 & -3.76 & 23.44 & 13.93 & 12.34 & 10.33 \\
\hline & -10 & 4.18 & 10 & 0.75 & -8.68 & 1.86 & 1.27 & 1.15 & 0.06 \\
\hline & 10 & -3.98 & 9 & -14.8 & -8.41 & -21.84 & -12.68 & -11.18 & -10.63 \\
\hline & 20 & -7.43 & 8 & -15.3 & -2.57 & -20.57 & -10.65 & -9.01 & -7.59 \\
\hline \multirow{4}{*}{$\gamma$} & -20 & -17.07 & 6 & -28.34 & -31.22 & -30.49 & -8.51 & -4.9 & -5.85 \\
\hline & -10 & -9.61 & 8 & -14.19 & -15.43 & -12.71 & -3.03 & -1.44 & -1.71 \\
\hline & 10 & 12.28 & 12 & 14.23 & 14.97 & 8.54 & 0.98 & -0.26 & -0.11 \\
\hline & 20 & 28.19 & 16 & 42.54 & 46.48 & 25 & 6.13 & 3.05 & 3.6 \\
\hline \multirow{4}{*}{$\delta$} & -20 & 0.22 & 10 & -0.44 & 5.13 & -0.7 & -0.44 & -0.41 & -0.03 \\
\hline & -10 & 0.11 & 10 & -0.22 & 2.5 & -0.34 & -0.22 & -0.19 & 0.02 \\
\hline & 10 & -0.1 & 10 & 0.21 & -2.38 & 0.32 & 0.2 & 0.19 & -0.02 \\
\hline & 20 & -0.2 & 10 & 0.4 & -4.65 & 0.63 & 0.4 & 0.36 & -0.03 \\
\hline
\end{tabular}

The following inferences can be obtained from Table 2:

(i) The optimal average profit is not sensitive for the changes of different cost parameters $C_{1}, C_{2}, C_{4}$, backlogging parameter $\delta$ and demand parameter $b$. However, it is more sensitive for the changes of location parameter $a$ of demand.

(ii) The optimal initial stock level $S$, shortage level $R$, time points and cycle length $T$ are insensitive with respect to $C_{4}, b$ and $\delta$ where as these are scarcely sensitive for the changes of the system parameters $C_{2}$ and $C_{5}$. For the remaining parameters, these are less sensitive. 
(iii) With the decreasing of demand parameters, the optimal values of $S, R, t_{0}, t_{1}, t_{2}$ and $T$ are highly sensitive. In these cases, the reverse effect has been observed.

(iv) As the value of parameter $\alpha$ decreases all the optimum quantities will be decreased.

\section{Concluding remarks}

In this paper, more realistic parameters such as price, frequency of advertisement, stock-dependent demand rate, deterioration and transportation costs for replenishment are considered in developing the model. The model has been formulated for items considering different scenarios depending on the highest stock-level and the stock-level of reorder point and incorporating the attractive advertisement in different media, the selling price of an item and the display of stock in the demand rate. The proposed demand situation can be seen to occur in cases where the customers arrive to purchase goods attracted by advertisement and displayed stock. This effect continues within a certain range of inventory level and beyond the lower level, only a limited number (may be considered as constant) of customers arrive to purchase the goods owing to such factors, viz. goodwill, good quality, genuine price-level of the goods, locality of the shop, etc. The present model can easily be extended to incorporate the different discounts (viz. All unit discounts, incremental discounts and fright discounts).

\section{Appendix}

Scenario 1: when $S \leq S_{0}$ and $R \geq 0$

In this scenario, the order quantity is $Q=S-R$. The inventory level $q(t)$ is given by

$$
q(t)=\exp \left(-\alpha t^{\beta}\right)\left[S-A^{\gamma}\left(a-b p+c S_{0}\right) \int_{0}^{t} \exp \left(\alpha u^{\beta}\right) d u\right],
$$

which is the solution of the differential equation

$$
q^{\prime}(t)+\theta(t) q(t)=-A^{\gamma}\left(a-b p+c S_{0}\right), \quad 0 \leq t \leq T
$$

with $q(t)=S$ at $t=0$ and $q(t)=R$ at $t=T$. The objective function can then be expressed as

$$
Z_{1}=\left[p\left(Q-D^{\prime}\right)-C_{3} Q-C_{\text {hol }}-C_{\text {tran }}-C_{a d v}-C_{4}\right] / T
$$

Scenario 2: when $S \leq S_{0}$ and $R<0$

The differential equations describing the instantaneous states of $q(t)$ in the interval $0 \leq t \leq T$ are given by

$$
\begin{aligned}
& q^{\prime}(t)+\theta(t) q(t)=-A^{\gamma}\left(a-b p+c S_{0}\right), \quad 0 \leq t \leq t_{2} \\
& q^{\prime}(t)=-A^{\gamma}\left(a-b p+c S_{0}\right) /[1+\delta(T-t)], \quad t_{2} \leq t \leq T
\end{aligned}
$$

with $q(t)=S$ at $t=0, q(t)=0$ at $t=t_{2}$ and $q(t)=R$ at $t=T$. The objective function is as follows:

$$
Z_{2}=\left[p\left(Q-D^{\prime}\right)-C_{3} Q-C_{\text {hol }}-C_{\text {sho }}-C_{\text {tran }}-C_{a d v}-C_{4}\right] / T
$$

Scenario 3 when $S_{0}<R<S<S_{1}$

In this scenario, the lot-size is $Q=S-R$ and the differential equation representing the inventory level $q(t)$ of this system is given by 
$q^{\prime}(t)+\theta(t) q(t)=-A^{\gamma}(a-b p+c q), \quad 0 \leq t \leq T$

with $q(t)=S$ at $t=0$ and $q(t)=R$ at $t=T$.

The objective function will be as follows:

$Z_{3}=\left[p\left(Q-D^{\prime}\right)-C_{3} Q-C_{\text {hol }}-C_{\text {tran }}-C_{a d v}-C_{4}\right] / T$

Scenario 4: $0 \leq R \leq S_{0}<S<S_{1}$

In this scenario, the lot-size is $S-R$ and the differential equations representing the inventory level $q(t)$ of this system are given by

$q^{\prime}(t)+\theta(t) q(t)=-A^{\gamma}(a-b p+c q), \quad 0 \leq t \leq t_{1}$

$q^{\prime}(t)+\theta(t) q(t)=-A^{\gamma}\left(a-b p+c S_{0}\right), \quad t_{1} \leq t \leq T$

with $q(t)=S$ at $t=0, q(t)=S_{0}$ at $t=t_{1}$ and $q(t)=R$ at $t=T$.

The objective function of this scenario is

$Z_{4}=\left[p\left(Q-D^{\prime}\right)-C_{3} Q-C_{h o l}-C_{t r a n}-C_{a d v}-C_{4}\right] / T$

Scenario 5: $S_{0} \leq S<S_{1}$ and $R<0$

In this scenario, the order quantity of this scenario is $Q=S+|R|$. The differential equations representing the inventory level $q(t)$ of this system are given by

$q^{\prime}(t)+\theta(t) q(t)=-A^{\gamma}(a-b p+c q), \quad 0 \leq t \leq t_{1}$

$q^{\prime}(t)+\theta(t) q(t)=-A^{\gamma}\left(a-b p+c S_{0}\right), \quad t_{1} \leq t \leq t_{2}$

$q^{\prime}(t)=-A^{\gamma}\left(a-b p+c S_{0}\right) /[1+\delta(T-t)], t_{2} \leq t \leq T$

with $q(t)=S$ at $t=0, q(t)=S_{0}$ at $t=t_{1}$. Again, $q(t)=0$ at $t=t_{2}$ and $q(t)=R$ at $t=T$.

The objective function of this scenario will be

$Z_{5}=\left[p\left(Q-D^{\prime}\right)-C_{3} Q-C_{h o l}-C_{s h o}-C_{t r a n}-C_{a d v}-C_{4}\right] / T$

Scenario 6: $S>S_{1}$ and $R>S_{0}$

The order quantity is $Q=S-R$ and the differential equations describing the instantaneous state of $q(t)$ in the interval $0 \leq t \leq T$ are given by

$q^{\prime}(t)+\theta(t) q(t)=-A^{\gamma}\left(a-b p+c S_{1}\right), \quad 0 \leq t \leq t_{0}$ 
$q^{\prime}(t)+\theta(t) q(t)=-A^{\gamma}(a-b p+c q), \quad t_{0} \leq t \leq T$

with $q(t)=S$ at $t=0, q(t)=S_{1}$ at $t=t_{0}$ and $q(t)=R$ at $t=T$

The corresponding objective function of this scenario is

$Z_{6}=\left[p\left(Q-D^{\prime}\right)-C_{3} Q-C_{h o l}-C_{\text {tran }}-C_{a d v}-C_{4}\right] / T$

Scenario 7: $S>S_{1}$ and $0 \leq R<S_{0}$

In this scenario, the order quantity is $Q=S-R$ and the differential equations describing the instantaneous state of $q(t)$ in the interval $0 \leq t \leq T$ are given by

$q^{\prime}(t)+\theta(t) q(t)=-A^{\gamma}\left(a-b p+c S_{1}\right), \quad 0 \leq t \leq t_{0}$

$q^{\prime}(t)+\theta(t) q(t)=-A^{\gamma}(a-b p+c q), \quad t_{0} \leq t \leq t_{1}$

$q^{\prime}(t)+\theta(t) q(t)=-A^{\gamma}\left(a-b p+c S_{0}\right), \quad t_{1} \leq t \leq T$

with $q(t)=S$ at $t=0, q(t)=S_{1}$ at $t=t_{0}, q(t)=S_{0}$ at $t=t_{1}$ and $q(t)=R$ at $t=T$.

The corresponding objective function of this scenario is

$Z_{7}=\left[p\left(Q-D^{\prime}\right)-C_{3} Q-C_{h o l}-C_{\text {tran }}-C_{a d v}-C_{4}\right] / T$

Scenario 8: $S_{1}<R<S$

In this scenario, the order quantity is $Q=S-R$ and the differential equation describing the instantaneous state of $q(t)$ in the interval $0 \leq t \leq T$ is given by

$q^{\prime}(t)+\theta(t) q(t)=-A^{\gamma}\left(a-b p+c S_{1}\right), \quad 0 \leq t \leq T$

with $q(t)=S$ at $t=0$ and $q(t)=R$ at $t=T$. The corresponding objective function of this scenario is

$$
Z_{8}=\left[p\left(Q-D^{\prime}\right)-C_{3} Q-C_{h o l}-C_{t r a n}-C_{a d v}-C_{4}\right] / T
$$

\section{References}

Abad, P. L. (1996). Optimal pricing and lot-sizing under of conditions of perishability and partial backordering. Management Science, 42, 1093-1104.

Anily, S., \& Federgruen, A. (1990). One warehouse multiple retailer systems with vehicle routing costs. Management Science, 36, 92-114.

Baker, R. C., \& Urban, T. L. (1988). A deterministic inventory system with an inventory-leveldependent demand rate, Journal of Operational Research Society, 39, 1823-1831.

Baumol, W. J. \& Vinod, H. D. (1970). An inventory theoretic model of freight transport demand. Management Science, 16, $413-421$.

Bhunia. A. K., P. Pal., Chattopadhyay. S. \& Medya. B. K.(2011). An inventory model of twowarehouse system with variable demand dependent on instantaneous displayed stock and marketing decision via hybrid RCGA, International Journal of Industrial Engineering Computations, 2, 351-368. 
Buffa, F., \& Munn, J. (1989). A recursive algorithm for order cycle that minimizes logistic cost, Journal of Operational Research Society, 40, 344-357.

Chang, C. T. (2004). Inventory model with stock-dependent demand and nonlinear holding costs for deteriorating items. Asia-Pacific Journal of Operational Research, 21, 435-446.

Constable, G.K., \& Whybark, D.C. (1978). The interactions of transportation and inventory decisions, Decision Science, 9(4), 688-699.

Datta, T. K. \& Pal, A. K. (1990). A note on an inventory model with inventory-level-dependent demand rate, Journal of the Operational Research Society, 41(10), 971 - 975.

Giri, B.C., Pal, S., Goswami A., \& Chaudhuri, K.S. (1996). An inventory model for deteriorating items with stock-dependent demand rate. European Journal of Operational Research, 95, 604610.

Goyal, S.K., \& Gunasekaran, A. (1995). An integrated production-inventory-marketing model for deteriorating items. Computers \& Industrial Engineering, 28, 755-762.

Goyal., S. K., \& Chang, C. T. (2009). Optimal ordering and transfer policy for an inventory with stock dependent demand. European Journal of Operational Research, 196, 177-185.

Kotler, P. (1971). Marketing decision making: a model building approach, Holt. Rinehart, Winston, New York.

Krishnaswamy, K. N., Kulkarni, N. G. \& Mathirajan, M. (1995). Inventory models with constraints and changing transportation cost structure. International Journal of Management and Systems, 11 , $91-110$.

Ladany, S., Sternleib, A. (1974). The intersection of economic ordering quantities and marketing policies. AIIE Trnsactions, 6, 35-40.

Luo, W. (1998). An integrated inventory system for perishable goods with backordering, Computers \& Industrial Engineering, 34, 685 - 693.

Mandal, B. N., \& Phaujdar, S. (1989a). An inventory model for deteriorating items and stockdependent consumption rate. Journal of Operational Research Society, 40(5), 483 - 488.

Mandal, B. N., \& Phaujdar, S. (1989b). A note on inventory model with stock-dependent consumption rate. Opsearch, 34, 156-166.

Mondal, B., Bhunia, A.K., \& Maiti, M. (2007). A model of two storage inventory system under stock dependent selling rate incorporating marketing decisions and transportation cost with optimum release rule. Tamsui Oxford Journal of Mathematical Sciences, 23(3), 243-267.

Mukhopadhyay, S., Mukherjee, R. N. \& Chaudhuri, K. S. (2004). An EOQ model with two-parameter weibull distribution deterioration and price-dependent demand, International journal of Mathematical Education in Science and Technology, 36, 25-33.

Padmanabhan, G. \& Vrat, P. (1995). EOQ models for perishable items under stock-dependent selling rate. European Journal of Operational Research, 86, 281-292.

Pal, A. K., Bhunia A. K. \& Mukherjee, R. N. (2004). A marketing-oriented inventory model with three-component demand rate dependent on displayed stock level (DSL). Journal of the Operational Research Society, 56, 113-118.

Pal. P., Bhunia A. K., \& Goyal. S. K.(2007). On optimal partially integrated production and marketing policy with variable demand under flexibility and reliability consideration via Genetic Algorithm, Applied Mathematics and Computation, 188, 525-537.

Pal, A.K., Bhunia, A.K., \& Mukherjee, R.N. (2006). Optimal lot size model for deteriorating items with demand rate dependent on displayed stock level(DSL) and partial backordering. European Journal of Operational Research, 175, 977-991.

Paul, K., Datta, T. K., Chaudhuri, K. S. \& Pal, A. K. (1996). An inventory model with two component demand rate and shortages. Journal of the Operational Research Society, 47, 10291036.

Subramanyam, S., Kumaraswamy, S. (1981), EOQ formula under varying marketing policies and conditions. AIIE Transactions, 22, 312-314.

Sana, S. \& Chaudhuri, K. S.(2004). On a volume flexible production policy for deteriorating item with stock-dependent demand rate. Nonlinear Phenomena in Complex system,7(1),61-68. 
Soni, H. \& Shah, N. H. (2008). Optimal ordering policy for stock-dependent demand under progressive payment scheme. European Journal of Operational Research, 184, 91-100.

Urban, T. L. (1992a). An inventory model with an inventory-level-dependent rate and relaxed terminal conditions. Journal of Operational Research Society, 41, 971-975.

Urban, T. L. (1992b). Deterministic inventory models incorporating marketing decisions, Computers \& Industrial Engineering, 22, 85-93.

Urban. T. L. (1995). Inventory models with the demand rate dependent on stock and shortage levels, International Journal Production Economics, 40, 21-28.

Zhou, Y. W., \& Yang, S. L. (2003). A two-warehouse inventory model for items with stock-leveldependent demand rate. International Journal of Production Economics, 95, 215-228. 